\title{
TELEJORNALISMO ALÉM DA TV: UMA DISCUSSÃO SOBRE OS TERRITÓRIOS CONTEMPORÂNEOS DA NOTÍCIA
}

\author{
TELEJOURNALISM BEYOND TV: A DISCUSSION ABOUT THE NEWS'S \\ CONTEMPORARY TERRITORIES
}

\author{
lana Coimbra \\ Pontifícia Universidade Católica de Minas Gerais \\ ianacoimbra@hotmail.com
}

\begin{abstract}
RESUMO: Neste artigo discutimos sobre o telejornalismo contemporâneo a partir da compreensão de que, ao passar por processos de convergência, ele não se limita mais ao ambiente televisivo. À medida que é inserido no ambiente virtual, ele rompe com o território hegemônico de origem, se torna um objeto digital e busca ocupar outros espaços e plataformas, incorporando estratégias e narrativas crossmidiáticas e transmidiáticas para informar. A partir de uma abordagem teórico-conceitual, discute-se como os conteúdos telejornalísticos transformados em objetos digitais passam a se abrigar, circular e flutuar pelo Facebook, Twitter e Instagram. Destaca-se como ponto relevante encontrado no estudo o processo de transição enfrentado pela TV como um território para receber e distribuir a informação nos lares, confrontado pelo surgimento dos meios digitais, que trazem uma força contrária, e espalham esses conteúdos em espaços diversos, num agenciamento desterritorializante da notícia. Logo, os grupos de comunicação buscam alcançar o público onde ele estiver, por meio de estímulos variados, o que também modifica o indivíduo de telespectador a espectador convergente.
\end{abstract}

PALAVRAS-CHAVE: telejornalismo; territórios; convergência; redes sociais; objetos digitais.

\begin{abstract}
In this article we discuss about contemporary telejournalism, from the understanding that, when going through processes of convergence, it is no longer limited to the television environment. As it is inserted in the virtual environment, it breaks with the hegemonic territory of origin, becomes a digital object and seeks to occupy other spaces and platforms, incorporating crossmedia and transmedia narratives to inform. From a theoretical-conceptual approach, it is discussed how the telejournalistic contents transformed into digital objects shelters, circulates and floats through Facebook, Twitter and Instagram. The transition process faced by TV as a territory to receive and distribute information in homes, confronted by the emergence of digital media, brings with it a counter force, and spread these contents in different spaces, in a deterritorializing news agency. Therefore, the communication groups seek to reach the audience where it is, by means of varied stimuli, which also modifies the viewer's individual into a convergent viewer.
\end{abstract}

KEYWORDS: telejournalism; territories; convergence; social media; digital objects. 


\section{Introdução}

Um dia cansativo, com outro qualquer. Chega-se em casa e deixam-se as chaves em cima do aparador da sala. Os sapatos também ficam ali, assim como a mochila. Ao conferir a hora, percebe-se que o telejornal acabou faz tempo. Respira-se fundo e reclama-se como o trânsito estava pesado. Passa-se pela TV no caminho até a cozinha, sem ligá-la. Vê-se o que tem na geladeira. Prepara-se um prato, ajeita-se a mesa, respirase fundo de novo. Antes da primeira garfada, pega-se o telefone, passa-se o dedo na tela, clica-se algumas vezes. Abre-se um aplicativo de rede social. Curte-se rapidamente algumas fotos da família que está viajando, comenta-se sobre o prato que o amigo acabou de preparar - e fez questão de postar - e ignora-se um vídeo da vizinha fazendo atividade física. Desliza-se o dedo pela tela até a postagem seguinte. O som que surge dali é conhecido. É a escalada do jornal. O mesmo que não deu para assistir pela TV mais cedo. E assim são os próximos minutos da noite: informando-se sobre o que aconteceu no país e no mundo pelo noticiário que já tinha sido exibido antes pelo canal aberto. Mas isso acontece agora usando o celular.

A cena descrita poderia acontecer nos Estados Unidos, no México, no Brasil, ou em qualquer outro país onde os grupos de comunicação - e telespectadores compreenderam que não é mais necessário oferecer - e consumir - conteúdo jornalístico produzido para a TV apenas por meio dela. A geração que a conheceu em preto e branco, que viu a chegada das cores, o frisson da tela plana, a implantação da TV digital, agora se vê diante de novas possibilidades de se entreter e de se informar a partir da convergência das mídias. O termo se tornou popular após o lançamento do livro A cultura da convergência, do pesquisador norte-americano Jenkins (2008), mas tem raízes no pensamento de McLuhan. Em 1969, McLuhan propôs a existência de uma relação entre os meios de comunicação, de forma que o conteúdo de qualquer meio ou veículo sempre tem como base um outro meio ou outro veículo. Cerca de 40 anos depois dessa ideia ser publicada, Jenkins (2008) se aprofundou no assunto e apresentou o termo convergência como o resultado de mudanças tecnológicas, industriais, culturais e sociais no modo como as mídias circulam, na inclusão do fluxo de conteúdos através de várias plataformas a partir do envolvimento e cooperação entre as indústrias midiáticas. Convergência é então proposta por Jenkins (2008) como um processo contínuo, uma série de interstícios entre diferentes sistemas de mídia, marcado pelo comportamento migratório de um público que navega pelas plataformas em busca de experiências, e cuja circulação de conteúdos depende da participação ativa dos indivíduos.

O pesquisador brasileiro Cannito (2010) acredita que a convergência conquistou espaço na sociedade a partir da proliferação dos celulares com múltiplas funções, cada vez mais portáteis, mais baratos e mais acessíveis. Assim, para ele, a convergência remodela tudo: "da linguagem à organização das empresas, que estão revendo seu plano de negócios e reorganizando seu modelo de produção" (CANNITO, 2010, p. 84). Finger (2017), por sua vez, acrescenta que o processo de convergência pode ser compreendido com a utilização das três telas - TV, computador e smartphones -, e propõe que o avanço e a convergência das novas tecnologias, e a evolução dos processos comunicativos mediados por elas, produziram efeitos em todos os meios de comunicação. Assim também acontece quando vemos afetarem e interferirem no universo da produção, da transmissão e da circulação dos noticiários televisivos. 
Assim, nos deparamos com o telejornalismo contemporâneo, em que os conteúdos noticiosos deixam a exclusividade da televisão e passam a circular também em sites, aplicativos e em redes sociais, como o Twitter, o Facebook e até mesmo o Instagram. Eles são impulsionados pela participação dos indivíduos que, nesses ambientes virtuais, curtem, comentam e compartilham o que assistiram, passando adiante o que lhes interessam. Dessa forma, o telejornalismo rompe com os horários preestabelecidos dentro de uma grade de programação e se liberta do tempo de duração estipulado para transmitir informações para o seu público original, alcançando inclusive outras audiências. Nesse processo de apropriação de espaços virtuais, o material televisivo se expande e enfrenta uma transição do modelo massivo para o interativo, essencial para que essas modificações constatas aconteçam. Daí a narrativa se modifica, podendo ganhar características crossmidiáticas e transmidiáticas, enquanto o conteúdo circula em busca de novos territórios e públicos.

\section{Uma questão de territórios}

Antes de avançar nessa discussão, é importante contextualizar brevemente o surgimento da TV, um meio de comunicação controverso, que modificou as formas de se consumir a informação ao longo de quase 100 anos desde que foi criada. Paternostro (1999) explica que o ser humano tem a necessidade de transmitir conhecimento como característica essencial para a sobrevivência da espécie. Assim, desde a troca de sinais de fumaça e das inscrições nas pedras, até o desenvolvimento dos meios mais modernos como a imprensa, sistematiza-se a capacidade de comunicação, num processo para agregar e incorporar inovações tecnológicas na ânsia por vencer barreiras, no tempo e no espaço. "É neste processo - urgente, avassalador - que surge a televisão, com a informação na sua forma mais dinâmica e universal: a imagem" (PATERNOSTRO, 1999, p. 21). A TV reuniu o que até então era pouco provável: o som que já se conhecia pelas rádios e as imagens que se via nos jornais. Foi inserida gradativamente no cotidiano das pessoas a partir da década de 1930, quando as primeiras emissoras se estabeleceram nos Estados Unidos, Inglaterra, e na França, padronizando modelos copiados mundo a fora, e alavancada no contexto da II Guerra Mundial. Na América Latina ela demorou um pouco mais para chegar. No Brasil, a primeira transmissão oficial só se deu em setembro de 1950, comandada pela TV Tupi de Assis Chateaubriand, voltada para um público limitado e elitizado. Ao longo do tempo a televisão caiu no gosto dos brasileiros, à medida que o eletrodoméstico teve a produção ampliada, os preços reduzidos, e outras emissoras surgiram, desenvolvendo programações que até hoje se ancoram num modelo que mistura entretenimento e informação ao longo das 24 horas do dia.

O resultado é que a TV foi conquistando espaço de destaque e prestígio nos lares. Acreditamos, então, que a partir desse processo, ao ser inserida no contexto familiar, a televisão se tornou um elemento territorializante, assim como os conteúdos produzidos e exibidos por ela, conforme explicam Deleuze e Guattari: "Os aparelhos de rádio ou de tevê são como um muro sonoro para cada lar, e marcam territórios" (DELEUZE; GUATTARI, 1997, p. 101). Na tentativa de encontrar uma definição e explicar o termo, Deleuze acreditava que o território "circunscreve, para cada um, o campo do familiar, do vinculante, marca as distâncias em relação a outrem e protege do caos" 
(ZOURABICHVILI, 2004, p. 23). Partimos, então, do ponto que a televisão estabeleceu nos lares um ambiente para se consumir a informação. Um espaço no qual a mídia, de certa forma, já tinha deixado marcas nas décadas anteriores com o rádio, mas que ganhou novas nuances, significados e potência com a chegada do último meio massivo a entrar na História, completando um sistema que começou com a imprensa no século XIX, como contextualiza Carlón (2014).

Com isso, o público foi acostumado a se deslocar até o espaço onde a televisão estava instalada - independentemente de onde fosse, a se assentar diante da tela e a ligá-la para acompanhar os programas e os noticiários exibidos em horários determinados, sejam eles de cobertura local ou nacional, pela manhã, na hora do almoço, ao longo da tarde, ou na hora do jantar. Foi dessa forma que a TV foi abraçada e abraçou a rotina. Assim como os sons que saem dela, as vozes dos jornalistas, dos apresentadores, as vinhetas, as chamadas, também ajudaram a estabelecer os muros e os limites desse território. Isso foi reforçado pela sequência estabelecida com a criação e a consolidação das grades de programação que organizam os conteúdos veiculados dentro de uma narrativa televisual única, ligada aos interesses e a agenda de cada emissora. De forma que os telejornais foram se identificando como o jornal da manhã, o que passa na hora do almoço, aquele do jantar. Logo, além de estabelecer um território fixo no espaço como eletrodoméstico, a programação televisiva veiculada a partir dele, passou também a estabelecer seu território no tempo, como explica Fechine (2014). Para a autora, a televisão funciona como uma espécie de relógio social capaz de pautar as práticas domésticas dos telespectadores, produzindo um sentido de presença. "A programação vai se fazendo construída em ato na medida mesmo em que se exibe: o fazendo da grade corresponde também ao se fazendo do dia" (FECHINE, 2014, p. 124). Ao associar hábitos de vida aos horários dos noticiários, numa articulação com práticas cotidianas e domésticas, tornou-se componente fundamental na construção do lar.

Na experiência televisiva esse sentir-se em casa constitutivo do hábito manifestase como um sentido associado, sobretudo, ao modo como nos colocamos à deriva no fluxo televisual, como passamos tempo com a programação, desfrutando da TV como uma agradável companheira, tomando gosto pela sua própria presença no dia a dia (FECHINE, 2014, p. 123).

A fixação de uma grade pautada pela repetição de programas em dias específicos, noticiários que entram e saem do ar nos mesmos horários, seguindo a mesma linha editorial, apresentados pelos mesmos jornalistas, cria um ritmo para a emissora e para os telespectadores. Daí firma-se o território, segundo Deleuze e Guattari (2004), que o encaram como o produto de uma territorialização dos meios e dos ritmos, sendo o ritmo uma potência de espaço e de tempo.

Precisamente, há território a partir do momento em que componentes de meios param de ser direcionais para se tornarem dimensionais, quando eles param de ser funcionais para se tornarem expressivos. Há território a partir do momento em que há expressividade do ritmo (DELEUZE; GUATTARI, 1997, p. 105).

Mas esse fluxo não é alimentado pelos mesmos conteúdos, porque as reportagens de cada dia são diferentes, já que os acontecimentos que fomentam os telejornais não se 
repetem e o ineditismo é de extrema relevância para que os telejornais sejam atraentes para o público. Portanto, temos sim, ritmo, continuidade, frequência, repetição, mas ao mesmo tempo esse território também é estabelecido pela diferença que se dá na formação contínua dos conteúdos que alimentam essa grade que se renova diariamente. E é esse conjunto que delimita o território do ponto de vista televisual. Então, quando o programa assistido chega ao fim, a TV é desligada e as pessoas deixam o ambiente. Até que no mesmo horário e local voltam a se reunir para assistir ao que Ihes interessa. Um comportamento em ciclo que se renova. Uma rotina. Um ato de repetição desse agenciamento territorial, sendo a repetição um resultado de um dever-querer no qual o sujeito cumpre um programa determinado por um destinador social, cultural e biológico (FECHINE, 2014).

[...] é preciso que a reiteração seja parte constitutiva de uma experiência de fruição inserida na continuidade do cotidiano. Nesse tipo de experiência, a presença familiar do objeto é parte do sentido produzido - algo como ligar a TV todo dia, no mesmo horário, no mesmo canal e nas mesmas condições que por si mesmas, provocam o sentir daquele sujeito (FECHINE, 2014, p. 120).

Silverstone (1996) também já escreveu sobre a importância do papel da TV nessa construção do sentimento de lar, descrita como produto do compromisso prático e emocional, com um determinado espaço, como a consciência de um ponto firme de referência para o qual voltamos. Nesse ponto firme, nesse território, nos sentimos em casa, em segurança, e cultivamos vínculos. Porém, para se ter acesso à informação telejornalística contemporânea não é mais necessário repetir esse ritual, ou mesmo manter uma cultura atrelada aos conceitos de tempo e de espaço para isso. Isso porque o desenvolvimento tecnológico permite que os conteúdos criados para e veiculados pela televisão transitem por diferentes plataformas pela internet, modificando a forma como 0 indivíduo se relaciona com os conteúdos audiovisuais aos quais tem acesso por meios diversos.

O século $X X$ viu o telefone, o cinema, o rádio, a televisão se tornarem objetos de consumo de massa, mas também instrumentos essenciais para a vida cotidiana. Enfrentamos agora o fantasma de mais uma intensificação da cultura midiática pelo crescimento global da Internet e pela promessa (alguns diriam ameaça) de um mundo interativo em que tudo e todos podem ser acessados instantaneamente (SILVERSTONE, 2002, p. 17).

A previsão de Silverstone (2002) se mostrou certeira. Podemos acessar e sermos acessados de qualquer lugar por meio dos dispositivos móveis conectados à rede mundial de computadores. Além disso, temos os produtos do cinema, da rádio e da televisão na palma da mão, unificados em um mesmo aparelho. Essa convergência traz possibilidades infinitas de transmissão de conteúdo, além de também modificar a forma de consumir esses conteúdos. Assim acontece um fenômeno que Deleuze e Guattari (1997) identificaram: entreabrimos o círculo fechado, hegemônico, dentro do território estabelecido pela TV. 
Agora, enfim, entreabrimos o círculo, nós o abrimos, deixamos alguém entrar, chamamos alguém, ou então nós mesmos vamos para fora, nos lançamos. Não abrimos o círculo do lado onde vêm acumular-se as antigas forças do caos, mas numa outra região, criada pelo próprio círculo. Como se o próprio círculo tendesse a abrir-se para um futuro, em função das forças em obra que ele abriga. $E$ dessa vez é para ir ao encontro de forças do futuro (DELEUZE; GUATTARI, 1997, p. 101).

Neste futuro, que já é tão presente, não dependemos mais de um eletrodoméstico preso à uma tomada num lugar fixo para se ter contato com os noticiários. As possibilidades de se ter acesso à informação telejornalística se multiplicaram, o que faz parte do devir do próprio telejornalismo. Portanto, como afirma Carlón: "aceitar que esse processo está acontecendo todos os dias é fundamental para começar a desenvolver estratégias que nos permitam analisar de forma mais profunda a era que vivemos de convergência e transmidiação" (CARLÓN, 2014, p. 29). Essas estratégias passam, assim, por reconhecer os territórios que extrapolam o ambiente televisivo.

\section{A era da convergência e os novos territórios}

Um dos resultados dessa era da convergência citada por Carlón (2014) é a proliferação de conteúdos audiovisuais nas redes, seja a partir da transmissão on demand ou por streaming. Finger e Souza (2012) explicam que a transmissão dos conteúdos televisivos nos dispositivos digitais, especialmente os móveis, pode acontecer de duas maneiras: em fluxo - por meio do streaming; ou por meio de arquivos - o que se dá a partir das tecnologias on demand. Os autores esclarecem que a transmissão por fluxo representa a reprodução ininterrupta do conteúdo, independentemente da escolha do receptor. Já a on demand é caracterizada pelo armazenamento desses conteúdos, que ficam à disposição das pessoas em um banco de dados e dependem da demanda em si, do desejo de alguém para serem exibidos.

Essas duas formas de distribuição são oferecidas nas plataformas digitais como aplicativos, sites e redes sociais de acordo com as características peculiares de cada meio. Por exemplo, pelo Twitter as reportagens exibidas nos telejornais pelos canais abertos ou fechados também podem ser consumidas on demand, assim que são publicadas nas timelines por meio dos tuítes feitos por quem administra o perfil em questão. Já pelo Facebook é possível fazer transmissões de telejornais inteiros ao vivo por streaming, ou então usar as lives conduzidas por repórteres ou apresentadores para adiantar o que será exibido no noticiário, ou abordar um assunto de uma maneira que ele tenha o tempo bem maior que o destinado originalmente na televisão, rompendo com a limitação imposta pela transmissão broadcast. Além do que, pode-se também contar com a participação do usuário para enviar perguntas ou comentários à produção, enquanto o jornalista ao vivo, segurando o telefone, conversa com a audiência por vídeo. Assim que essa transmissão chega ao fim, ela mesma se torna um produto on demand, ao ser transformada em um conteúdo audiovisual que fica à disposição do público na timeline dos perfis corporativos, ao lado das matérias jornalísticas publicadas individualmente pelas organizações, compondo um cardápio audiovisual virtual.

A rede social Instagram, desenvolvida originalmente para publicar fotos pessoais a 
partir dos perfis de quem está na plataforma, também oferece possibilidades para a transmissão de vídeos por streaming e on demand. As lives e os stories são exibidos em fluxo, um vídeo atrás do outro, continuamente, por streaming. Se quem estiver assistindo quiser interromper o que está vendo, pode-se clicar no canto direito da tela para passar para frente, ou deslizar o dedo na tela para assistir ao que outro perfil postou usando a mesma ferramenta, na mesma plataforma. Da mesma maneira, é possível mudar de canal de uma programação televisiva convencional. É importante registrar que esses vídeos ficam no ar por apenas 24 horas, desaparecendo em seguida. Alguns podem ser selecionados pelo administrador do perfil que decide por oferecê-los como vídeos fixos, para ficarem em destaque e poderem ser consumidos de outra forma - neste caso on demand. Semelhantemente, acontece com a ferramenta mais recente oferecida pelo Instagram, o IGTV. Nela, os usuários podem editar e inserir vídeos maiores, com mais tempo de duração, de uma forma parecida como a que outra plataforma referência na exibição de vídeos, o YouTube, oferece. Assim, esses conteúdos também ficam disponíveis para que o usuário escolha o que vai assistir na hora mais conveniente, seja pelo computador, telefone, tablet, ou mesmo por smartTV. Ao comparar os dois modelos de transmissão, streaming e on demand, Cannito (2010) esclarece que um modelo não é superior ao outro, mas ambos são estéticas diferentes. Eles coexistem, e é o público quem escolhe o que mais lhe interessa de acordo com o momento e conveniência. Essa possibilidade novamente reforça a característica interativa desses novos territórios ocupados pelos conteúdos telejornalísticos nos meios virtuais.

Ao navegar por essas plataformas, é possível constatar que várias empresas de comunicação têm investido nesses caminhos para expandir o conteúdo produzido originalmente para a televisão. Nos Estados Unidos, a primeira emissora a ser fundada no país, a NBC, distribui material telejornalístico pelo aplicativo NBCNews, na qual os principais noticiários têm um espaço reservado, pelo Twitter, pelo Facebook e até mesmo pelo Instagram - onde prioriza lives e stories para completar as informações transmitidas pela televisão ou para mostrar os bastidores do universo televisivo. O mesmo caminho é adotado pelo grupo Televisa, no México, que compartilha os conteúdos por meio do canal de notícias @noticierostelevisa no Facebook, Twitter, Instagram e pelo aplicativo que leva o mesmo nome dessa divisa da empresa. No Brasil, a Rede Globo também segue padrão semelhante ao implantado pelas empresas internacionais, ao oferecer 0 material telejornalístico por aplicativos como GloboPlay e apresentar perfis corporativos dos telejornais pelo Twitter e pelo Facebook. Logo, ao entrar nessas redes e deslizar a tela em busca de conteúdos de interesses diversos, como perfis de amigos, ou de celebridades, de empresas que prestam serviços ou que vendem produtos, tem-se a possibilidade de esbarrar em reportagens, entrevistas e coberturas jornalísticas de qualquer tipo de acontecimento. Assim, o telejornalismo deixa de pertencer só a TV, e passa a ser um produto comunicacional também da TV, mas que faz parte de uma ação desterritorializante - movimento no qual se deixa um território, em busca de outros, segundo Zourabichvili (2004), e que pode se enquadrar no que Deleuze e Guattari (2004) identificaram como uma função agenciada:

Que adquire independência suficiente para formar ela própria um novo agenciamento, mais ou menos desterritorializado, em vias de desterritorialização. Não há necessidade de deixar efetivamente o território para entrar nesta via; mas aquilo que há pouco era uma função constituída no agenciamento territorial, torna- 
se agora o elemento constituinte de um outro agenciamento, o elemento de passagem a um outro agenciamento (DELEUZE; GUATTARI, 2004, p. 116).

Tal citação ilustra perfeitamente a relação do telejornalismo veiculado pela TV, e pelos seus desdobramentos fora dela, por aplicativos e mídias sociais. Assim, ao mesmo tempo em que os conteúdos telejornalísticos deixam a exclusividade da televisão, eles não a abandonam, nem a negam, ao seguirem uma perspectiva convergente, e não excludente. Desterritorializam-se, e buscam novos territórios, ao mesmo tempo que mantêm as raízes fincadas no meio de origem e que até então permanece como o principal. Isso diferencia os telejornais que buscam se expandir para outras plataformas do webjornalismo, que já nasceu e se desenvolveu a partir dos meios e ferramentas digitais.

\section{Objeto digital}

Todavia, quando o telejornalismo deixa de pertencer exclusivamente à TV e se expande para outras plataformas, o conteúdo se transforma. Ao romper a barreira de uma única tela, ele se torna um objeto digital, como sugerido pelo pesquisador coreano Hui. "Objetos digitais são simplesmente objetos na Web, como vídeos no YouTube, perfis no Facebook, imagens no Flickr, e assim por diante, compostos por dados e estruturados por esquemas ou ontologias que podem ser difundidos como metadados" (HUI, 2012, p. 380). Para Hui (2012), os objetos digitais se relacionam com outros objetos - como, por exemplo, os objetos técnicos nos quais se enquadram os smartphones, tablets, smartTVs; e também com os objetos naturais, como podem ser consideradas as informações, os acontecimentos, que sobretudo são as matérias primas do telejornalismo. O pesquisador coreano, em entrevista a Geert Lovink, esclareceu que é necessário refletir então sobre essas relações porque a investigação dos objetos digitais é uma tentativa de retrabalhar o objeto polo e redefinir sua relação com o sujeito (HUI; LOVINK, 2016). E isso faz sentido, porque ao mudar de meio, ao se transformar em algo diferente, as relações entre conteúdos e as pessoas que os consomem mudam. Para Hui, "a Web age como uma interface entre usuários e objetos digitais, e como um mundo onde esses objetos se escondem e se revelam - em termos físicos e metafísicos" (HUI, 2012, p. 381). Assim, a web e as redes digitais como ambientes de circulação, também agem como mediadores, de forma que fazem a ligação entre a notícia produzida para exibição no formato televisivo e esses outros espaços, em outras plataformas. Objetos digitais em novos territórios.

Este é o cenário do telejornalismo contemporâneo. Os noticiários tradicionais continuam entrando e saindo do ar dentro de uma programação fixa ao serem transmitidos pelas emissoras de canal aberto ou fechado. Mas eles também estão presentes na internet inseridos nos sites oficiais dos grupos aos quais pertencem, em aplicativos próprios apresentando a notícia por streaming ou on demand, e também marcam presença nas redes sociais a partir de perfis corporativos, publicando e expandindo o que produzem para além da TV convencional. E, assim, quem consome esse conteúdo passa a ter a oportunidade, e o poder, de curtir, comentar e compartilhar o que assistiu, fazendo a notícia circular por ambientes e públicos que ela de outra forma não alcançaria. 
Porém, nessas interfaces nem sempre o conteúdo telejornalístico está sozinho. Ali ele se encontra ao lado do que é produzido por outras frentes, fontes diversas, como o jornalismo alternativo, por influenciadores digitais e pelo usuário comum que tem nos meios virtuais espaço para publicar o que dificilmente encontraria abertura na mídia convencional. Por exemplo, diante de um furacão como o Florence, que avançou sobre a costa leste dos Estados Unidos em setembro de 2018, qualquer pessoa podia pegar um telefone e começar a fazer lives ou stories para narrar o que se passava no local onde estava. Assim, podia-se mostrar a força do vento, os efeitos nas casas dos vizinhos e inserir depoimentos de quem também testemunhava o acontecimento e a violência do furacão, de forma amadora mas com informações relevantes, que despertam o interesse público. Esse conteúdo nas timelines podia surgir ao lado de um material produzido por um repórter de uma emissora tradicional, como a NBC, que fez a cobertura in loco com toda a estrutura disponível de uma equipe de reportagem. No entanto, apesar de recursos diferentes, de olhares também diferentes, tanto o conteúdo produzido por equipes profissionais quanto o feito pelo indivíduo comum na condição de testemunha, disputam a atenção e o tempo de quem está do outro lado da tela, selecionando o que vai assistir por meio dos cliques.

Contudo, Becker (2016) acredita que mesmo diante do surgimento de formas paralelas de se informar pela internet, a grande imprensa continua sendo o lugar onde a maioria da população recorre para acompanhar os principais acontecimentos do mundo em busca de fontes confiáveis. Por isso, segundo a pesquisadora, talvez o jornalismo nunca tenha sido tão necessário e relevante para contribuir com informações sérias e fomentar o debate público, principalmente nas redes sociais, que têm se mostrado terreno fértil para as fake news. Segundo Paulino, Empinotti e Porto (2013, p. 63-64), diante desse cenário, "a intenção é adaptar a televisão para os novos modos de consumo que estão nascendo, e que vão transformar toda a área, inclusive a mudança do broadcast atual para uma transmissão feita pela internet". Isso justifica o investimento das empresas de comunicação nas plataformas digitais, que propagam os conteúdos produzidos para a televisão de outras formas, a fim de desafiarem fronteiras e irem em busca de uma audiência que está além do telespectador.

O que também muda nesse cenário é a forma de se referir à pessoa que consome a informação além da TV. Esse público, além de acompanhar os conteúdos audiovisuais pela internet ou pelas redes sociais, também tem a oportunidade de interagir com o que assiste diante das possibilidades oferecidas pelos grupos de comunicação nesses ambientes e até mesmo de contribuir com as narrativas. Alguns autores chamam esse indivíduo de interator (MACHADO, 2007), outros de prosumidor (BRUNS, 2008; SCOLARI, 2008), ou ainda de agentes intercomunicadores (WILLIAMS, 2016; PRIMO, 2013). O pesquisador Mario Carlón (2012) prefere chamar de sujeito espectador televisivo convergente. Com base nessa compreensão, e diante do que acreditamos se adequar de uma maneira mais precisa à percepção estabelecida neste trabalho, passaremos a nos referir às pessoas que têm um papel central no telejornalismo contemporâneo, que também consomem a notícia fora da TV, como espectadores convergentes. 


\section{Crossmídia e transmídia}

Voltando ao conceito de objeto digital estabelecido por Hui (2012), quando o conteúdo que até então era disponibilizado somente pela televisão muda de meio, quando ele sai desse território hegemônico e se torna um objeto digital, acreditamos que ele o faz por meio da incorporação de estratégias crossmidiáticas. A palavra crossmídia vem do inglês crossmedia, numa tradução literal "mídia cruzada" (FINGER; SOUZA, 2012). O termo envolve o processo de difusão de conteúdo em diversos meios, abrindo caminho para a interação.

Canavilhas (2018) recorre a Veglis (2012) para definir crossmídia como a produção de qualquer conteúdo, notícias, música, texto e imagem, para mais de uma plataforma, como TV, web e rádio, dentro de uma mesma empresa jornalística. Mas o conceito vai além, porque o material publicado em diversas plataformas não deve ser necessariamente idêntico, e o que foi divulgado em uma mídia deve completar o que foi publicado em outra. Por exemplo, uma reportagem exibida pela TV pode ter trechos aproveitados numa postagem do Instagram, inserir o link para assistir à versão completa no site, e acrescentar um depoimento do repórter sobre os bastidores por meios dos stories. Depois o mesmo assunto pode ser publicado no Facebook, com a inclusão de arquivos inéditos, como fotografias ou vídeos, que completam a história. Pelo Twitter, o apresentador do telejornal pode divulgar uma informação de última hora, atualizar o assunto. O importante, segundo Finger (2012), é respeitar as peculiaridades e características de cada meio. Porém, o mais importante não é a adaptação dos conteúdos para diferentes canais, mas sim a forma como eles estão interligados. Por exemplo, quando acaba uma entrevista ao vivo para a televisão, o entrevistado pode continuar a prestar esclarecimentos pelo stories do Instagram ou numa live do Facebook, sem limite de tempo, como num telejornal televisivo. Ou seja, quando os conteúdos telejornalísticos são transformados em objetos digitais, e ao serem inseridos num ambiente crossmidiático, faz-se necessária a criação de outros objetos digitais para compor essa narrativa. Dessa forma, amplia-se a quantidade e o alcance dos conteúdos que partiram de uma abordagem televisiva, mas não se prenderam a ela. O mesmo acontece no contexto do telejornalismo transmidiático.

No entanto, Alzamora (2017) esclarece que a narrativa transmídia se dá na distribuição em mídias distintas e plataformas tecnológicas de conteúdos associados entre si, cuja articulação depende da participação do telespectador. Alzamora e Tárcia (2012) acrescentam que a narrativa começa em um meio e termina em outros para aproveitar o melhor de cada um, numa forma inovadora de produção e circulação, miscigenando gêneros e formatos pela integração entre as lógicas da transmissão e do compartilhamento. Tal procedimento é possível ser feito nas redes sociais a partir das ferramentas que elas oferecem. Por exemplo: uma reportagem vai ao ar pela TV sobre os 17 anos da queda das Torres Gêmeas nos Estados Unidos e pode ser complementada por uma live com sobreviventes respondendo a perguntas dos espectadores convergentes. Também pode contar com vídeos de arquivo de 11 de setembro de 2001 no IGTV, enviados pelo público. Nos stories, os repórteres podem mostrar os bastidores da reportagem e convidar o público a acompanhar a cobertura completa por todas as plataformas disponíveis e a enviar relatos sobre a tragédia. $\mathrm{Na}$ timeline, podem ser postados fotos e vídeos da matéria que foi exibida, abrindo a oportunidade para os 
espectadores convergentes curtirem, comentarem e compartilharem. E assim segue a criação de objetos digitais que flutuam por diversas plataformas, a partir do que foi desenvolvido para a televisão.

Fechine e Rêgo (2017) acrescentam que a transmidiação no jornalismo pode ser compreendida como um conjunto de ações adotadas pelas corporações, seguindo um planejamento estratégico de produção e disponibilização de conteúdos de forma diversificada, reforçando a condição da participação do espectador. Fechine e Moreira (2016) consideram ainda que na transmidiação os projetos são desenvolvidos em torno de uma mídia de referência por onde os conteúdos se propagam e se expandem, incorporando outras plataformas na cadeia criativa. Eles ressaltam que, para dar certo, o público deve ter a capacidade de se conectar, sobretudo nas redes sociais, para moldar a circulação desse conteúdo, desses objetos digitais que estarão interligados e conectados para compor uma única narrativa, enquanto circulam por diversos territórios.

Canavilhas (2018) propõe então que o jornalismo transmídia deve atender a três condições para ser configurado como tal: 1) ser multiplataformas com conteúdos expandidos ou adaptados para a internet; 2) contar com histórias compostas por partes independentes, mas suficientemente significativas para serem usadas como pontos de entrada, permitindo que o usuário navegue de forma personalizada e 3) oferecer ao público a possibilidade de contribuir, mesmo sendo esta uma das maiores dificuldades do jornalismo transmidiático, porque é preciso estabelecer se o papel dos espectadores convergentes será limitado à participação de baixo envolvimento, apenas comentando nas publicações feitas, por exemplo, ou se devem influenciar no desenvolvimento das reportagens. Nesse caso a interatividade pode ser de baixa complexidade, apenas com comentários, ou de alta complexidade, ao acrescentar conteúdos que mudam ou expandem o curso da narrativa. Mas ela não pode deixar de existir. A partir desse entendimento, é possível compreender que tudo isso proporciona a criação de um rizoma no ambiente fora da TV, usando aqui mais um conceito de Deleuze, sobre o qual Pelbart discorreu.

\footnotetext{
Num rizoma entra-se por qualquer lado, cada ponto se conecta com qualquer outro, não há um centro, nem uma unidade presumida - em suma, o rizoma é uma multiplicidade (como se vê, todas essas características prenunciavam a geografia imaterial da Internet, para cuja assimilação filosófica parecíamos tão pouco preparados) (PELBART, 1997, p. 3).
}

Cada uma das possibilidades oferecidas pelas redes sociais proporciona que os espectadores convergentes tenham acesso a notícias de alguma forma. Assim, a partir dessas ferramentas eles podem se conectar com a informação por meio de uma foto da timeline no Twitter, por meio de uma transmissão ao vivo de um acontecimento que se passa naquele instante no Facebook, ou por stories no Instagram, atualizando uma cobertura jornalística. Dessa forma, toma-se a consciência de um todo e, se for o caso, até vai-se em busca de mais informações, pelo site, por aplicativo, ou pela televisão, até que o assunto, ou o interesse, se esgote. Isso estimula um comportamento migratório do público, como afirma Jenkins (2008), ao discorrer sobre o perfil de quem circula entre as plataformas em busca de experiências, o que envolve mudanças significativas na forma de se produzir e de consumir a notícia pelos meios de comunicação. 


\section{Considerações finais}

Portanto, é possível observar que, nessas mudanças de meios, plataformas e territórios, as identidades dialogam, sem que haja a superação completa de uma tecnologia pela outra. Os meios de compartilhamento dos conteúdos jornalísticos podem coexistir, e em seu devir, estão em busca de caminhos e modelos para que esses objetos digitais possam se abrigar, circular, flutuar, e até mesmo gerar novos objetos digitais.

Se estamos falando de devir, é bom ressaltar que ele nunca é imitar, conforme Deleuze e Guattari (1997) acreditam. "Não se imita; constitui-se um bloco de devir, a imitação não intervém senão para o ajuste de tal bloco, como numa última preocupação de perfeição, uma piscada de olho, uma assinatura" (Ibid., p. 128). Portanto, o desafio é encontrar formas específicas de se comunicar em cada plataforma, de criar novos objetos digitais, na tentativa e busca de evitar simplesmente copiar e colar conteúdos, e assim atrair o espectador convergente para a narrativa construída. Por fim, para Deleuze e Guattari (1997), as máquinas e a tecnologia sempre serão chaves singulares que abrem ou fecham um agenciamento, um território, possibilidades de se informar e de produzir a informação, conforme abordado ao longo deste artigo.

Então, se ao longo das décadas a televisão criou um território para receber e distribuir a informação nos lares, os meios digitais surgiram trazendo uma força contrária através de plataformas diversas. Assim, ao invés de aglutinar, eles espalham esses conteúdos originalmente pensados e produzidos para a TV em espaços variados. De maneira que promovem a circulação dos conteúdos nas redes virtuais na tentativa de alcançar um público que já rompeu com o limite do território de uma tela fixa, e se torna independente de locais pré-determinados para assistir ao que lhe interessa. Isso é feito por meio de estratégias e estímulos diferentes, que transformam o telespectador tradicional em um espectador convergente, porque não são somente os conteúdos telejornalísticos que enfrentam processos que os modificam em objetos digitais desterritorializados. Afinal, os indivíduos que consomem essas informações também passam por processos de convergência, que modificam hábitos, costumes, e toda uma cultura da forma de se assistir aos telejornais que por anos foram atrelados ao tempo e ao espaço. Logo, temos objetos digitais permeando sites, aplicativos, redes sociais, invadindo as timelines e disputando o tempo e a atenção dos espectadores convergentes em ambientes diferentes daqueles de origem. Dessa forma, acontece o processo de reterritorialização desses conteúdos, que em cada plataforma encontram um público, uma lógica de veiculação e um novo espaço para ocupar. Diante dessas possibilidades, as emissoras passam também a desenvolver outros objetos digitais para alimentar esses espaços recém-conquistados com informações que complementam as narrativas que seguem tendo a TV como base, mas sem se limitar a ela. Então, vemos o telejornalismo se transformar, com o desafio de se adaptar a uma lógica de produção convergente, e de existir em um contexto em que os conteúdos se desterritorializam, e se reterritorializam de forma cíclica, de forma a se manter relevante e atual diante da pluralidade de informações. Com o objetivo de ampliar os caminhos para informar, se comunicar e interagir com públicos diversos nas linguagens peculiares a cada um, isso ocorre pelo meio que for, no território que for. 


\section{Referências}

ALZAMORA, G. C. Televisão em Semiose: mídia, intermídia, transmídia. São Paulo, Anais da Compós: 2017.

ALZAMORA, G.; TÁRCIA, L. Convergência e transmídia: galáxias semânticas e narrativas emergentes em jornalismo. Brazilian Journalism Research. v. 8, n. 1, 2012.

BECKER, B. Televisão e telejornalismo: transições. Estação das letras e cores. São Paulo, 2016.

BRUNS, A. Blogs, wikipedia, second life and beyond: from production to produsage. New York: Peter Lang, 2008.

CANAVILHAS, J. Journalism in the twenty-first century: to be or not to be transmedia? In.: GAMBARATO, R. R.; ALZAMORA, G. C. (Org). Exploring transmedia journalism in the digital age. IGI Global, 2018, p. 01-14.

CANNITO, N. A TV na era digital: interatividade, convergência e novos modelos de negócio. Summus Editorial, 2010.

CARLÓN, M. En el ojo de la convergencia: los discursos de los usuarios de Facebook durante la transmissión televisiva de votación de la ley de matrimonio igualitario. In: CARLÓN, M.; FAUSTO NETO, A. (Ed.). Las políticas de los internautas: nuevas formas de participación. Buenos Aires: La Crujía, 2012, p. 173-194.

CARLÓN, M. Repensando os debates anglo-saxões e latino-americanos sobre "o fim da televisão". In.: CARLÓN, M.; FECHINE, Y. (Org.). O fim da televisão. Confraria do vento: Rio de Janeiro, 2014, p. 11-33.

DELEUZE, G.; GUATTARI, F. Mil platôs: capitalismo e esquizofrenia. Volume 4. Editora 34: São Paulo, 1997.

DELEUZE, G.; GUATTARI, F. O que é a filosofia. Editora 34. São Paulo, 2004.

FECHINE, Y. Elogio à programação: repensando a televisão que não desapareceu. In.: CARLÓN, M.; FECHINE, Y. (Org.). O fim da televisão. Confraria do vento: Rio de Janeiro, 2014, p. 114-131.

FECHINE, Y.; MOREIRA, D. G. Dispositivo midiático de participação nas interações transmídias: explorando o conceito a partir das ações da Rede Globo no seriado Malhação. Galaxia. São Paulo, 2016.

FECHINE, Y.; RÊGO, S. C. R. Estratégias transmídias e construção do éthos do telejornal: o caso do Jornal da Record News. In: XXVI Encontro Anual da Associação Nacional dos Programas de Pós-graduação em Comunicação - Compós, 2017, São Paulo. Anais da Compós 2017. São Paulo: Compós, 2017. v. 1. p. 1-15. 
FINGER, C. Crossmedia e transmedia: desafios do telejornalismo na era da convergência digital. In: En Questão, Porto Alegre. V. 18, n. 2, p. 121-132, jul/dez.2012.

FINGER, C. O telejornalismo agora está no Facebook: uma narrativa da reportagem de televisão para as redes sociais. In: XL Congresso Brasileiro de Ciências da Comunicação -INTERCOM, 2017, Curitiba. Anais do XL INTERCOM. Curitiba: INTERCOM, 2017. p. 115.

FINGER, C.; SOUZA, F. C. de. Uma nova forma de ver TV no sofá ou em qualquer lugar. Revista Famecos: mídia cultura e tecnologia. Porto Alegre, v. 19, n. 2, p. 373-389, maio/agosto, 2012.

HUI, Y. What is a digital objetct. In: MONNIN, A.; HALPIN, H. (Ed.). Metaphilosophy 43, p. 380-395, jul. 2012.

HUI, Y.; LOVINK, G. Digital objects and metadata scheme. E-flux journal. N. 78. 2016. Disponível em: <https://www.e-flux.com/journal/78/82706/digital-objects-and-metadataschemes/>. Acesso em: 09 dez. 2018.

JENKINS, H. A cultura da convergência. São Paulo: Aleph, 2008.

MACHADO, A. O sujeito no ciberespaço: modos de enunciação no cinema e no ciberespaço. São Paulo: Paulus, 2007.

MCLUHAN, M. Os meios de comunicação como extensões do homem. São Paulo: Cultrix, 1969.

PATERNOSTRO, V. Í. O texto na TV: Manual de telejornalismo. Editora Campus, Rio de Janeiro, 1999.

PAULINO, R. de C.; EMPINOTTI, M. L.; PORTO, N. Possibilidades de integração entre televisão e gadgets móveis: uma experiência de segunda tela. In: EMERIM, C.; PAULINO, R. (Org.) Ensaios sobre televisão e telejornalismo. Florianópolis: Insular, 2013, p. 63-76.

PELBART, P. P. In.: DELEUZE, G.; GUATTARI, F. Mil platôs: capitalismo e esquizofrenia. Volume 4. Editora 34: São Paulo, 1997, p. 05-06.

PRIMO, A. Interações mediadas e remediadas: controvérsias entre as utopias da cibercultura e a grande indústria midiática. In: PRIMO, A. (Org.). Interações em rede. Porto Alegre: Sulina, 2013, p. 13-32.

SCOLARI, C. Hipermediaciones. Elementos para una teoría de la comunicación digital interativa. Gedisa editorial. Barcelona, 2008.

SILVERSTONE, R. Por que estudar a mídia? 3ed. São Paulo: Loyola, 2002.

SILVERSTONE, R. Televisión y vida cotidiana. Trad. Alcira Bixio. Buenos Aires: Amorrortu 
Editores, 1996.

VEGLIS, A. From cross media to transmedia reporting in newspaper articles. Publishing Research Quarterly, v. 28, n. 4, p.313-3242012.

WILLIAMS, R. Televisão: tecnologia e forma cultural. PucMinas. Belo Horizonte, 2016.

ZOURABICHVILI, F. O vocabulário de Deleuze. Tradução André Telles. Rio de Janeiro, 2004.

Recebido em dia 02 de outubro de 2018. Aprovado em dia 25 de novembro de 2018. 